\title{
A bibliometric analysis of the Journal of Transport and Supply Chain Management
}

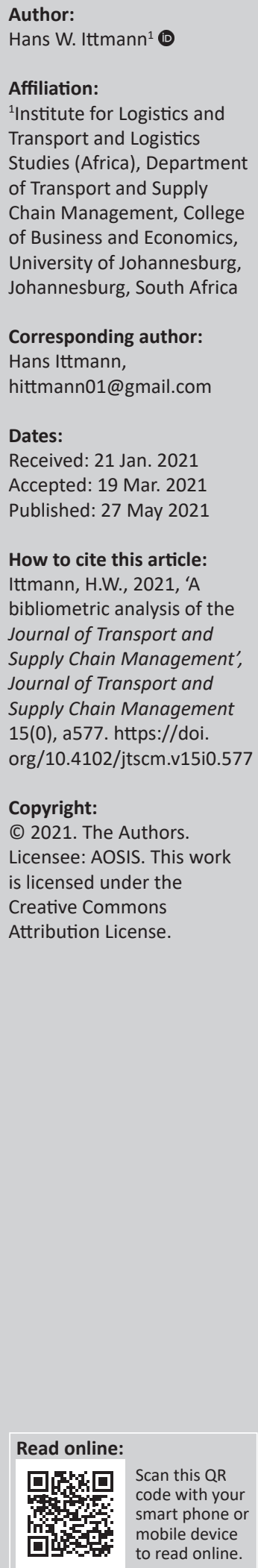

Background: At the start of the 20th century a need was identified for a dedicated scholarly journal that would publish research, case studies, new trends, et cetera covering transport, logistics and supply chain management. The Department of Transport and Supply Chain Management of University of Johannesburg launched the Journal of Transport and Supply Chain Management (JTSCM) in 2007.

Objectives: The purpose of this study is to determine, through bibliometric analysis, what the impact of the journal is, which is measured over a period of 13 years.

Method: The impact of the journal was determined through a variety of quantitative methods. A bibliographic database populated with journal data, was used to visualise co-authorship relationships using the tool, VOSviewer.

Results: Over the period 2007 to 2019, a total number of 197 articles were published in the journal. Using Google Scholar, a total of 1987 citations for all the articles published were found. The top 10 articles with the highest number of citations are listed with numbers ranging from 27 to 160 respectively. Tables are presented with the most productive authors, the number of articles by authors from local academic institutions, the private and public sectors as well as the number of articles by international authors. A few co-authorship visualisation maps were produced which shows 'clusters' of research teams, networks or communities.

Conclusion: The Journal of Transport and Supply Chain Management has made a significant impact over the period analysed as the number of citations and number of abstract and article views attest to.

Keywords: bibliometric analysis; transport; supply chain management; logistics; scholarly journal.

\section{Introduction}

At the start of the 20th century, several logistics and supply chain management initiatives were initiated in both government and the scientific environment in South Africa. It gave recognition to the growing importance of this critical field to the economy. A National Advanced Manufacturing Technology Strategy (AMTS) was developed under the auspices of the National Advisory Council of Innovation (NACI) for the Department of Science and Technology (Republic of South Africa 2005a). The strategy recognised the importance of logistics, and one of the recommendations of the strategy was the establishment of a logistics centre of innovation. During the same period, the National Department of Transport (NDoT) launched the National Freight Logistics Strategy (NFLS) (Republic of South Africa 2005b). This strategy was developed to address the key challenges in this environment as captured in the strategy's problem statement:

The freight system in South Africa is fraught with inefficiencies at system and firm level. There are infrastructure shortfalls and mismatches; the institutional structure of the freight sector is inappropriate, and there is a lack of integrated planning. Information gaps and asymmetries abound; the skills base is deficient, and the regulatory frameworks are incapable of resolving problems in the industry. (Republic of South Africa 2005b:4)

Various academic institutions in the country had already established logistics and supply chain management departments or were in the process of getting these off the ground. During the same period, the Council for Scientific and Industrial Research (CSIR) held a workshop on global logistics in cooperation with the Georgia Institute of Technology of the United States (GeorgiaTech) (CSIR 2002). Local delegates from the South African private and public sectors as well as academics from several local and international universities attended this workshop and gave presentations. Finally, the first State of Logistics Survey was published by the CSIR in 2005 (CSIR 2005). This 
survey addressed important issues in the logistics sphere in South Africa, whilst it contained data on freight in the country, both on road and on rail. Included as well was the total cost of logistics for the country, which was presented as a percentage of the country's gross domestic product (GDP). After this first survey, it was published annually for 10 years but unfortunately the publication was terminated in 2014 .

The one gap that was still not addressed was a scholarly journal dedicated to the field of logistics and supply chain management. In 2007, the Department of Transport and Supply Chain Management at the University of Johannesburg (UJ) initiated and published the first edition of the Journal of Transport and Supply Chain Management (JTSCM). This was a timely action by this department. Both scientists and practitioners now had a vehicle to publish their research and practical work in a local South African journal.

This study endeavours to give a detailed bibliometric analysis of the material that has been published in JTSCM from volume 1, published in 2007, up to volume 13, published in 2019 , a period of 13 years with 13 volumes. The most recent volume, volume 20, published in 2020 is excluded from this analysis. The study addresses the following research issues: (1) What are the number of articles published and the article citations over the period? (2) Which are the top-cited articles of the journal? (3) Who are the most productive and influential authors and from which institutions? (4) What are the publication patterns of the journal? (5) What are the main topics published in the journal? The overriding objective of this analysis is to obtain a sense of the impact this journal has had over the 13-year period.

A journal with a high impact is one that is highly influential in its field. This is typically denoted by the journal's impact factor which is a measure of the frequency with which an average article in a journal has been cited in a particular year. Citations are thus a critical indicator of impact. The journal will also have an impact if there are articles that influence government policy in both the transport and supply chain management fields. Issues that would be of interest is to determine whether there are patterns related to South African-specific topics such as the road-to-rail debate, e-tolling, transport infrastructure, public transport and others. Furthermore, does the journal attract international authors and articles? In addition, impact can also be measured by journal accreditation and journal indexing on sites such as International Bibliography of the Social Sciences (IBSS), Scopus, Scientific Electronic Library Online (SciELO), and International Scientific Indexing (ISI).

An outline of the rest of the article is as follows: In the second section, the founding, mandate and funding of the journal are outlined. A short literature review is presented in the third section, and the bibliographic analysis is discussed and presented in the fourth section. This is followed by a discussion of the analysis in the fifth section and the conclusion is provided in the sixth section.

\section{Journal founding, mandate and funding}

As indicated earlier, the journal with the title, the JTSCM, was founded in 2007 by the Department of Transport and Supply Chain Management of UJ. The first editor was Ms Beverly Kujawa from the same department at UJ. In her first editorial, she outlined the purpose of the journal as:

The journal serves as an independent publication for scientific contributions in the field of transportation and supply chain management, i.e. logistics, operationsmanagement, purchasing management, distribution management, warehousing management, transportation (all modes), production planning and related fields. Theoretical, empirical, and applied articles are considered for publication. It is the challenge of the Journal to present a diverse range of articles covering a variety of subject matter within the arena of transport and supply chain management. (Kujawa 2007:1)

An additional field of interest, 'transport', was included, broadening the scope and breadth of scientific areas that could be covered in this new journal.

Researchers and practitioners, locally and internationally, were invited to submit articles for publication in this new journal. The vision was that these would 'contribute to expertise, growth and productivity in the fields of transport and supply chain management'. Contributors would be able to share the latest research, new trends, important noteworthy practices as well as case studies with those involved in these two critical sectors enabling them to stay abreast of the needs, requirements and developments within these dynamic disciplines.

Initially an annual volume, in book form, containing all the articles for the volume of that calendar year was printed and published. From 2012 this changed, and the journal became 'open access', with articles published on a continuous basis as soon as the article was accepted for publication. All previous articles were also made available in this manner (see https: / / jtscm.co.za/index.php/jtscm). A limited number of printed copies of the book that includes all the articles for the past calendar year is still printed.

To enhance the stature of the JTSCM, it was necessary to appoint an independent editor. This was done in 2012 when emeritus Professor Stephen Kruger took responsibility for this task. At that time, it was also decided to outsource the administrative activities associated with the publication of the JTSCM to African Online Scientific Information Systems (AOSIS), a professional management company that manages a range of academic journals. This arrangement commenced in the beginning of 2013 (Kruger 2013). By 2020, Prof Kruger, with the assistance of the co-editor Mr Tatenda Mbara, was still managing the journal. An editorial board is in place, 
consisting of local and international academics as well as representatives from the private sector.

Initially, the funding required for publishing the journal was provided by the Department of Transport and Supply Chain Management of UJ. This, however, changed in January 2017 when page fees were introduced. This practice is in line with many international and local journals (JTSCM editorial board meeting on 26 October 2017, Kingsway Campus, University of Johannesburg). Every year the page fees are increased with the objective of getting to a point where the journal is fully self-funded. Initially, when the page fees were introduced, these were relatively low, with the department still proving a substantial portion of the funding required. Over time, by slowly increasing the page fees, this contribution will reduce and ultimately become relatively small or zero.

Obviously, the impact of page fees on article submissions will be monitored to ensure that it does not negatively impact such submissions.

The journal is accredited by the Department of Higher Education (DHE) as well as Scopus. The Scopus accreditation only occurred in 2018, with the result that articles published from 2019 onwards is available on Scopus.

\section{Literature review}

Bibliometric reviews are not uncommon. Formally bibliometrics is defined as the use of statistical methods to analyse books, articles and other publications. The objective is to determine through a quantitative assessment what the academic quality of a journal is, as well as authors, by statistical methods such as citation rates (Van Leeuwen 2004).

Wang, Lim and Lyons (2019) give a general overview of the International Journal of Logistics Research and Applications as part of the 20th anniversary of the journal. It covers the period 1998-2017 and endeavours to identify leading trends that have affected the journal over this period. A whole range of bibliometric aspects are included in the analysis such as the publication and citation evolution of the journal, the most-cited articles, the most productive and influential authors, institutions, countries, etc.

Similar analysis has been conducted for other journals and the analysis of two journals, namely, Review of Managerial Science (RMS) (Mas-Tur et al. 2020), an international journal, and a local journal, ORiON, journal of the Operations Research Society of South Africa (ORSSA) (eds. Kruger \& Van Vuuren 2019), both dedicated towards other disciplines, are briefly mentioned. In the case of RMS, a bibliometric overview of the publication and citation structure of the journal is presented from its inception in 2007 until 2020. The analysis cover topics of articles published in the journal as well as the authors, their institutions and countries. It gives an up-to-date comprehensive overview of the history of RMS. In contrast, ORSSA celebrated its 50th anniversary in 2019, and as part of the celebration published a book that covered the history of the society since its inception in 1969 (eds. Kruger \& Van Vuuren 2019). One chapter in the book is devoted to ORiON, the peer-reviewed, scholarly journal of ORSSA (eds. Kruger \& Van Vuuren 2019). This flagship journal of the society was launched in 1985 and the analysis covers 34 volumes published over the period 19852018. The founding and mandate of the journal is, inter alia, discussed; and a comprehensive analysis is then given of articles published over this period. In conclusion, there is a reflection on the state of ORiON and the challenges faced by the editorial team.

Bibliometric analysis has been performed in similar ways for specific supply chain-related journals or for specific Supply Chain Management (SCM) topics. For a specific logistics or SCM journal, see Wang et al. (2019), whilst such an analysis around a specific topic is presented in Ghalehkhondabi, Ahmadi and Maihami (2020). Several additional examples, both transport and supply chain management related, are given below:

- Optimisation in supply chain management (Movahedipour et al. 2016) - Some 1610 articles published from 1994 to March 2016 were used in this bibliometric analysis to obtain a sense of the current state of research in optimisation in SCM and to identify the potential areas of future research.

- City logistics (Hajduk 2017) - Here the aim was to identify any trends and the dynamics of changes in city logistics. Host databases, such as ISI Web of Science (WoS), Scopus, Elsevier, Emerald and EBSCO, were used as sources of the literature. The bibliometric analysis was conducted using the software package, VOSviewer.

- Reverse logistics and closed loop supply chain management (Kazemi, Modak \& Govindan 2019) - These two areas are universally recognised as environmentally friendly practices that could help in greening supply chains. As part of the 55th volume anniversary of the International Journal of Production of Research (IJPR), this review was aimed at investigating studies conducted on the topic of reverse logistics and close loop SCM in IJPR over the period 2000 until July 2017.

- Reverse logistics research (Wang et al. 2016) - Reverse logistics is considered a critical component of SCM, and this timely and comprehensive literature review was conducted to identify opportunities for future research in the area.

- Supply chain management (Yalcin, Shi \& Rahman 2020) An up-to-date review of global contributions in SCM publications between 1998 and 2017, using scientometric analysis, was aimed at identifying prevailing and recent research trends and topics in the field. The analysis showed a general increase in the number of SCM articles over the period. An attempt was also made to identify future research needs in SCM.

- Green and sustainable logistics (Ren et al. 2019) - This review presented a quantitative and qualitative understanding of the evolutionary trends, knowledge structures and literature gaps in this research field. A total 
of 306 studies published from 1999 to 2019 were retrieved, elaborated on and synthesised. A whole range of aspects were analysed bibliographically.

- Air transport - A highly informative, and relevant, retrospective bibliometric analysis was performed using 1438 articles published in the Journal of Air Transport Management (JATM) (Tanriverdi, Bakır \& Merkert 2020). These are all articles published in this journal up to the outbreak of COVID-19. The aim of the analysis was to draw lessons from and evaluate whether past pandemics and economic crises influenced JATM publications in terms of both frequency and impact. It was found that these were not dominant in their impact although it was noticeable that the terms 'recovery, crisis and disruption' were important key words after these events.

- Transportation research-Thejournal Transportation Research (TR) was established in 1967 with the vision of promoting multidisciplinary research on transport systems. Over the years, the journal has expanded into six separate journals, TR Parts A-F, addressing policy and practice, methodological, emerging technologies, transport and environment, logistics and transportation review and traffic psychology and behaviour, within the transport sector, respectively. A bibliometric analysis, which included all publications in the different TR journals, was part of the first half century celebrations of TR (Modak et al. 2019). It is a comprehensive analysis to identify leading trends in all the TR journals over the period 1967-2016. The analysis covers aspects such as impact, topics, authors, universities and countries, whilst bibliographic coupling, such as co-citation, citation, coauthorship and co-occurrence of key words, are analysed, and these relationships are visually presented.

- Transportation Research Part B: Methodological Transportation Research Part B: Methodological (TRPart B) became an independent journal in 1979 and its focus was on methodological development of transportation science. Jiang, Bhat and Lam (2020) performed a separate bibliometric analysis of the TR mentioned above, covering the entire lifetime of TR-Part B over the period 1979-2019. In total, 2697 articles were included in the analysis. A similar comprehensive analysis was conducted leading to very insightful bibliometric findings. For both TR and TR-Part B, the data for the bibliometric analysis were collected from the WoS Core Collection database.

It is clear from the above that there is a strong drive to analyse journals, and specifically their impact, as well as research areas in SCM. The latter is important as research gaps can be identified, trends within the research area can be determined, one can obtain a sense of the most productive authors as well as those making the biggest impact through considering the number of citations of their work.

\section{Bibliometric analysis}

Bibliometric methods use bibliographic data from a publication database. In the case of the JTSCM, most of the data were extracted from the JTSCM website. The method, or process followed, to obtain the data used in this study is summarised as follows (all the data used were obtained on 11 December 2020, whilst some similar numbers were obtained in mid-April 2020):

- The full set of articles was accessed from the official webpages of the JTSCM as administered by AOSIS Publishing (https://jtscm.co.za/index.php/jtscm). For each article, the title, author(s), affiliation(s) and key words, where listed, were extracted. Two further metrics for each article are also provided in the website, namely, total abstract views and total article views. The numbers are questionable as they seem to be the wrong way around.

- From the data provided on the website, the total number of abstracts viewed for all articles over the period 2007-2019 were 589 585, whilst the total number of articles viewed were 1709 693. One would have thought that the abstracts viewed were much higher, whilst the articles viewed (downloaded) would be much less. On the contrary, the numbers presented in this article are 'correct', that is, the number for abstracts viewed is used for articles viewed and vice versa. A number is also given for citations of articles, but a different source was used (see the next point) in this study, as it is not clear where and how the numbers given in the website are obtained.

- For the number of citations, a whole range of sources can be used, namely, WoS, Scopus, Google Scholar (GS) and several others. The above mentioned are considered as the three main comprehensive citation databases (Bar-Ilan 2010). For this study, GS was used. The reason for this is based on Michigan State University (MSU) (2020) where a comparison is outlined between PubMed, WoS and GS. The overriding advice provided when deciding which of these databases to use is: 'it depends on what you're trying to do'. Google Scholar was selected because it 'is not a human-curated database but a search engine of the whole internet which narrows the results to "scholarly" ones based on machine automated criteria'. Google Scholar searches for material based on the criteria for inclusion as 'scholarly' and these include books, journal articles, reports, theses, preprints and other types of sources. In addition, WoS (2019) acknowledges that GS is more liberal in attributing citations than, for example, WoS. Using GS to extract citations for all articles in JTSCM ensures articles are equally treated.

- An exhaustive process, using GS, was conducted for each of the articles published in JTSCM to obtain the number of citations for every specific article. The numbers reflected were obtained on 11 December 2020.

- In order to draw some bibliographic graphs, a bibliographic database needed to be created which can then be used with special software. Although JTSCM is accredited with Scopus, only the articles published in 2019 and 2020 are indexed in Scopus. Journal of Transport 
and Supply Chain Management articles are also not indexed in WoS but Dimensions, ${ }^{1}$ an alternative but to Scopus and WoS, does contain all the JTSCM articles, see https: / / app.dimensions.ai / discover/publication? search_mode=content\&or_facet_source_title=jour. 1150232. Dimensions allow one to create an account with free access. After building the bibliographic database, using all 197 articles obtained from Dimensions, the VOSviewer software tool was used to graphically visualise some of the data. VOSviewer is a software tool developed by researchers from the University of Leiden in the Netherlands. It is used for constructing and visualising bibliometric networks (VOSviewer 2021). Networks may include journals, researchers or individual publications, and networks from these sources can be constructed based on citation, bibliographic coupling, co-citation or co-authorship relations. In this article, the focus was on co-authorship. The reason for the latter is mainly data related. VOSviewer support files created in WoS, Scopus, Dimensions and PubMed. This implies that VOSviewer can read files from these four sources and perform analysis with the data obtained in this way. A data file created with Dimensions was used in VOSviewer.

This section presents the results obtained from the bibliometric analysis. Various trends are presented as well as a variety of issues of interest, giving a sense of the impact of the journal.

In Table 1 some basic statistics are shown, comparing numbers extracted mid-April 2020 to those extracted in midDec 2020.

This gives an indication of the interest in JTSCM articles over a period of 8 months. About 111263 researchers viewed abstracts of articles over this period, whilst 62483 articles were viewed (or downloaded) over the same period. One should point out that these numbers are not absolute numbers, implying that the same researcher might have viewed the same abstract or article more than once.

\section{Number of articles per volume}

A total number of 197 articles were published in the journal over the period 2007-2019. Of these, 133 covered supply chain management issues; whilst the rest, 64, were devoted to transport topics. Theoretical, empirical and applied articles were going to be considered for publication when the journal was launched. In this regard, the breakdown for three types of articles is 91, 64 and 42, respectively. There is some subjected judgement on designating the type of article. Figure 1 shows the number of articles published per volume (or year).

\footnotetext{
1.Dimensions is a linked research knowledge system that re-imagines discovery and access to research. Developed by Digital Science in collaboration with over 100 access to research. Developed by Digital science in collaboration with over 100 leading research organisations around the world, Dimensions brings togethe grants, publications, citations, alternative metrics, clinical trials, patents and polic documents to deliver a platform that enables users to find and access the most relevant information faster, analyse the academic and broader outcomes of research and gather insights to inform future strategy. For more information about the product, visit https://dimensions.ai (Dimensions 2021).
}

TABLE 1: Numbers of abstracts and articles viewed over a period of 9 months.

\begin{tabular}{lcc}
\hline Date & Abstracts viewed & Articles viewed (or downloaded) \\
\hline Mid-December 2020 & 1709693 & 589585 \\
Mid-April 2020 & 1598430 & 527102 \\
Difference & $\mathbf{1 1 1 2 6 3}$ & $\mathbf{6 2 4 8 3}$ \\
\hline
\end{tabular}

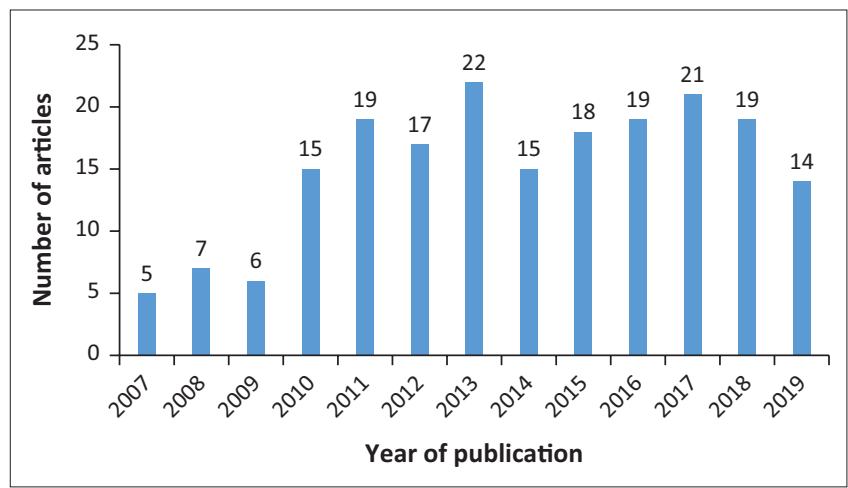

FIGURE 1: Number of articles per volume over the period 2007-2019.

Initially the journal struggled to gain momentum but the average number of articles per volume is now around 15 per volume. One would, obviously, like to see a continuous increase in the number of articles published per volume. It is difficult to pinpoint what the reasons are for this not being the case, especially for the decrease in the number of articles published from 2018 onwards. One can only speculate around this. Maintaining a high standard with quality articles is, and remains, an overriding objective. Over time, the acceptance rate of articles decreased with the concomitant increase in quality articles but typically resulting in a lower number of published publications.

The impact of the $25 \%$ rule from the DHE is exceedingly difficult to quantify.

This rule requires that no more than $25 \%$ of articles published in one volume can be from the same institution in South Africa. This rule can have a few implications, namely, articles, which have been accepted, need to be kept for the next volume. As authors are keen on publishing their work, they may decide to submit their articles to other journals, mainly international journals, which are not affected by this policy of the DHE. A further incentive for those in academic institutions to publish in international journals is that it 'strengthens' their CVs, which could be of advantage when promotion is considered or when a researcher is considered, or reconsidered, for professional rating by the National Research Foundation.

\section{Citations}

As stated above an exhaustive process was followed, using GS, to obtain the citations for all 197 articles published over the period being reviewed. Figure 2 shows the number of citations for articles published in each of the 13 volumes. No apparent pattern can be observed from this figure. At the time of this study, the total number of citations was 1987. Self-citations are included in the number of citations but to 


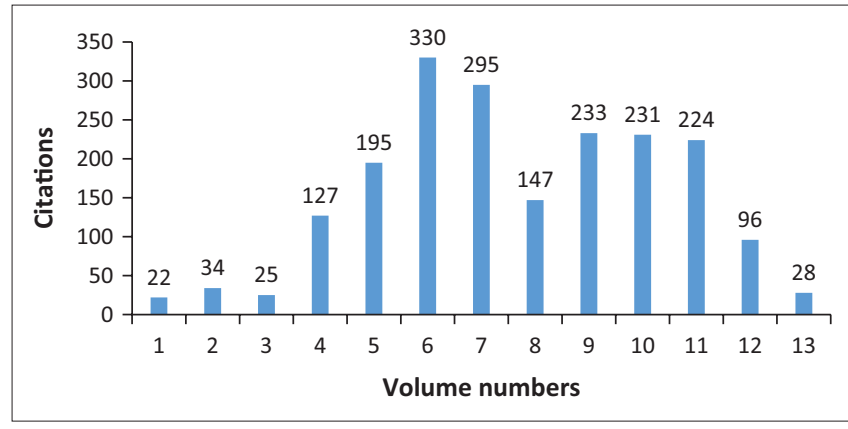

FIGURE 2: Number of citations per volume over the period 2007-2019.

determine the magnitude of this, is challenging. The citations for 2018 and 2019 are low compared to the earlier 3 years and can largely be attributed to the shorter time that elapsed since the publication of the articles in those 2 years.

It is, however, interesting to note that the total number of citations increased from 1539 to 1987 over a period of 8 months (mid-April 2020 to 11 December 2020). The increase is 448 which signifies an increase of just less than 30\%. Can this imply the start of bigger visibility of articles published in the journal?

As mentioned in the literature review, a similar analysis was performed by the ORSSA in assessing its journal ORiON (eds. Kruger \& Van Vuuren 2019). In this case, the analysis was for a period of 34 years, with two issues of the journal published biannually. A total of 237 articles were published, and the total number of citations was 1381 as of July 2019. Google Scholar was also used to determine the number of citations. Although operations research is a different discipline, the journal, ORiON, is also a South African journal, such as JTSCM, and this makes for interesting comparison of two journals. Over a much shorter time, with less than half the number of volumes published, and with less articles, the number of citations of the JTSCM, 1987, is substantially higher. The average number of citations per article for ORiON is 5.8; whilst for JTSCM, it is 10.0. Both journals are South African based and both aim to serve the local environment; however, transport and logistics cover a much broader area with more practitioners, researchers and academics, all aspects that can explain the difference in the number of citations. Furthermore, these are two different disciplines.

Figure 3 gives the number of citations for each of the articles published in the JTSCM over the 13-year period.

There are 197 articles, and each article was numbered from 1 to 197 . The first five articles in volume 1 is numbered $1-5$; seven articles in volume 2 is numbered 6-12; six articles in volume 3 is numbered $12-18$ and similarly for all subsequent articles. Figure 4 presents the same information but in this case per volume.

From Figures 3 and 4, it is very noticeable that the citations for one article overshadow all the others. The number of

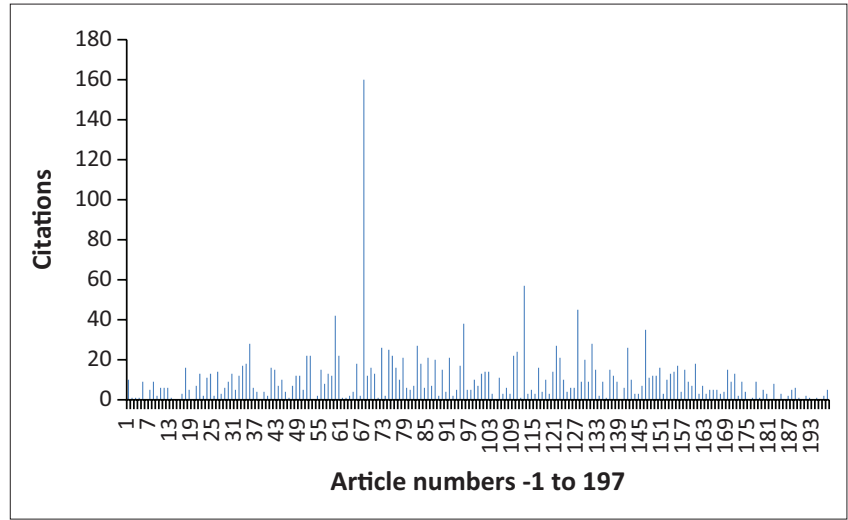

FIGURE 3: Number of citations per article for all articles published over the period 2007-2019.

citations for this specific article is 160, with the second highest being 57 and then a number above 20; but for the rest of the articles, the citations are low.

In Table 2, the top 10 articles with the highest number of citations are listed. The articles with the highest and third highest citations address issues around procurement in the public sector in South Africa. The high number of citations is not surprising because of the procurement system, called 'supply chain management' in the public sector, and it is one of the main challenges within this sector as well as one of the main contributors to corruption in the country. The SCM, or procurement, protocols of government are ignored, misused or not applied properly. This has led to a lot of studies on the topic. In total, 10 articles are devoted to procurement issues, but there are few of these that build on each other to illustrate that one research aspect leads to the next, especially in the South African context. This implies lack of research collaboration in the country.

The rest of the articles amongst these top 10 addresses a variety of topics in logistics, supply chain management and transport. Transport, transportation and related policy issues (Walters 2014, Number 5 on the citation list) are covered in 24 articles addressing a wide range of transport matters. This again shows that the research topic is addressed once but there is no 'follow-up or continuation' to extend, strenghten or deepen the research. As Rosenberg (1976) stated 'the generation of knowledge is based on previous knowledge and affects future research' and this is not visible. The same pattern can be observed for the rest of the articles with high citations. What it does illustrate is the diversity of topics covered in the journal which is typical of this discipline in South Africa as is the case with most disciplines in the country. The number of researchers is limited and the topics they work on vary considerably, with the result that there are not many researchers working on the same topic or research area. In addition, many of the articles address and research local issues, and very few articles contribute to international issues or cutting-edge research. A large portion of articles are thesis work published by students; and in many cases, the articles are co-authored by the study leader or promoter. 


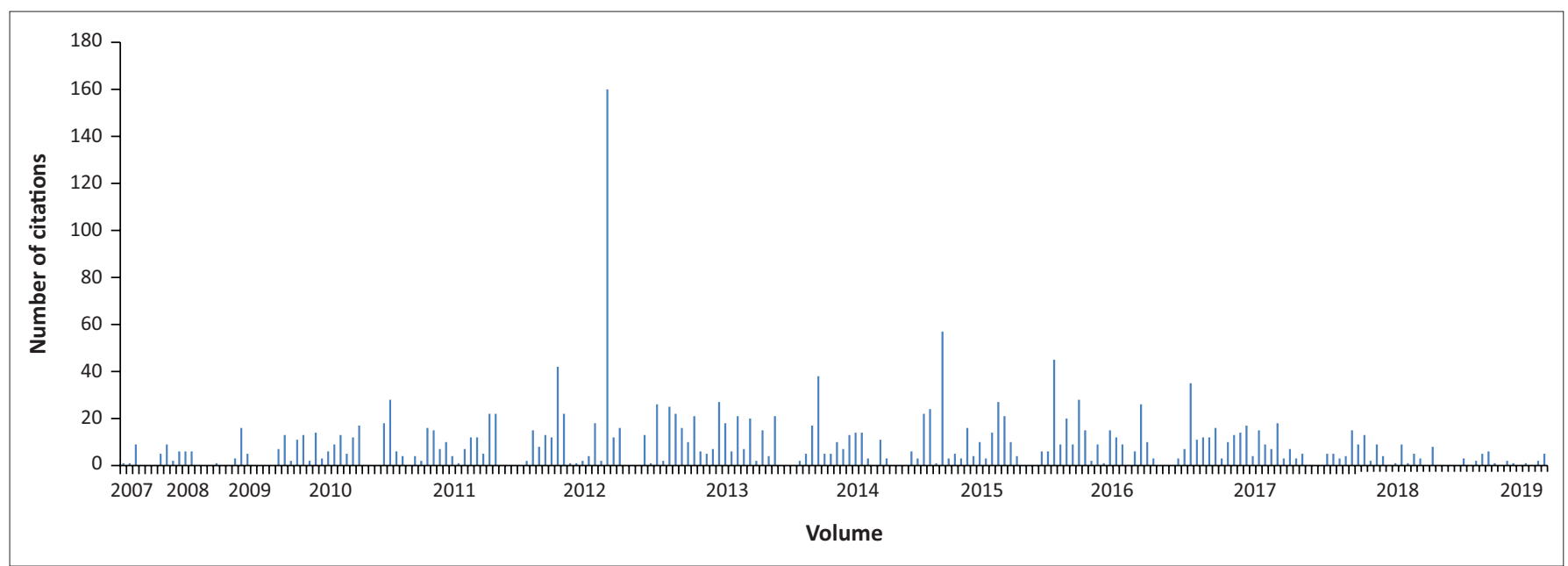

FIGURE 4: Number of citations per article per volume published over the period 2007-2019.

TABLE 2: Top 10 articles with the highest number of citations.

\begin{tabular}{|c|c|c|c|c|c|}
\hline Title of article & Author(s) & Affiliation & Volume & Article number & Citations \\
\hline Procurement challenges in the South African public sector & $\begin{array}{l}\text { Intaher M. Ambe, Johanna A. } \\
\text { Badenhorst-Weiss }\end{array}$ & UNISA & 6 & 67 & 160 \\
\hline The impact of big data and business analytics on supply chain management & Hans W. Ittmann & UJ & 9 & 112 & 57 \\
\hline Skills requirements in the supply chain industry in South Africa & Gert Heyns, Rose Luke & UJ & 6 & 59 & 42 \\
\hline Public transport policy implementation in South Africa: Quo vadis? & Jackie Walters & UJ & 8 & 95 & 38 \\
\hline $\begin{array}{l}\text { The impact of green supply chain management in small to medium } \\
\text { enterprises: cross-sectional evidence }\end{array}$ & $\begin{array}{l}\text { Chengedzai Mafini, Asphat } \\
\text { Muposhi }\end{array}$ & VUT & 11 & 146 & 35 \\
\hline $\begin{array}{l}\text { Supply chain performance attributes for the fast-moving consumer goods } \\
\text { industry }\end{array}$ & Madhu Bala, Dinesh Kumar & India & 5 & 35 & 28 \\
\hline $\begin{array}{l}\text { Supply chain integration: a qualitative exploration of perspectives from } \\
\text { plastic manufacturers in Gauteng }\end{array}$ & $\begin{array}{l}\text { Yvonne Vermeulen, Wesley } \\
\text { Niemann, Theuns Kotzé }\end{array}$ & UP & 10 & 131 & 28 \\
\hline $\begin{array}{l}\text { The influence of logistics integration on information sharing and business } \\
\text { performance: the case of small and medium enterprises in South Africa }\end{array}$ & $\begin{array}{l}\text { Richard Chinomona, R.I. David } \\
\text { Pooe }\end{array}$ & VUT & 7 & 82 & 27 \\
\hline $\begin{array}{l}\text { The influence of information sharing, supplier trust and supplier synergy } \\
\text { on supplier performance: the case of small and medium enterprises }\end{array}$ & $\begin{array}{l}\text { David Pooe, Chengedzai Mafini, } \\
\text { Vandrys W. Loury-Okoumba }\end{array}$ & VUT, UJ & 9 & 121 & 27 \\
\hline
\end{tabular}

UNISA, University of South Africa; UJ, University of Johannesburg; UL, University of Limpopo; VUT, Vaal University of Technology; UP, University of Pretoria.

From the analysis, it can be seen that about one-third of the articles have 0 (14 articles), 1 (15), 2 (15) or 3 (16) citations, whilst in total, 128 articles have 10 or less citations. The latter represents almost two-thirds of the articles. In the Scimago Journal and Country Rank 1996-2019 bibliometric indicators database (SJR 2020), where countries are ranked according to the number of publications over the 20-year period, South Africa is ranked 35 out of 240 countries, territories, etc. The average citations per article are also calculated; and for South Africa, this value is 14.59 . The content of the Scimago database is sourced from Scopus. Scopus is the world's largest abstract and citation database (Scopus 2020), but citations are based on peer-reviewed research literature. Comparisons are, thus, not compatible with that of GS. Nevertheless, the average citation number of 10 per article for JTSCM gives an indication that whilst the JTSCM is a great vehicle to publish articles, there is still a long way to go to make a real impact both locally and internationally.

\section{Journal authorship}

In total, 259 'unique' authors contributed to the articles published in JTSCM over the period 2007-2019. This section is devoted to an analysis of the most productive authors, the affiliations of authors, the number and countries of international contributors as well as those from the private sector. Furthermore, co-authorship relationships are presented.

\section{Productive authors and authors achieving the biggest impact}

In Table 3, the top 10 most productive authors are shown with their affiliations as well as the volume of the journal in which the articles were published. The authors are all from different universities in South Africa. In addition, the centres of 'excellence' or the four universities, which have dedicated logistics and supply chain management departments, are all represented amongst these top 10. These are the Department of Logistics from Stellenbosch University (US), the Department of Transport and Supply Chain Management of UJ, the Department of Business/ Applied Management of University of South Africa (UNISA) and the Department of Business Management of University of Pretoria (UP). Table 4 confirms this as these four academic institutions are at the top of the list of contributors to the JTSCM. From Table 3, it is also noticeable that collaborators from these four institutions feature strongly, namely, Havenga, Simpson, de Bod with 
TABLE 3: Top 10 productive authors with affiliation and volume numbers in which articles appeared.

\begin{tabular}{|c|c|c|c|c|}
\hline Author & Affiliation & Articles & Volume & Number of articles \\
\hline \multirow[t]{8}{*}{ J.H. Havenga } & US & 18 & 4 & $\mathrm{x} 3$ \\
\hline & & & 5 & $x 3$ \\
\hline & & & 6 & x3 \\
\hline & & & 7 & $x 2$ \\
\hline & & & 8 & $x 2$ \\
\hline & & & 9 & - \\
\hline & & & 10 & $x 2$ \\
\hline & & & 12 & $x 2$ \\
\hline \multirow[t]{10}{*}{ Jackie Walters } & UJ & 14 & 1 & - \\
\hline & & & 4 & - \\
\hline & & & 5 & - \\
\hline & & & 6 & - \\
\hline & & & 7 & - \\
\hline & & & 8 & - \\
\hline & & & 9 & $x 3$ \\
\hline & & & 10 & $x 2$ \\
\hline & & & 12 & - \\
\hline & & & 13 & $x 2$ \\
\hline \multirow[t]{7}{*}{ J.A. Badenhorst-Weiss } & UNISA & 12 & 4 & - \\
\hline & & & 5 & x3 \\
\hline & & & 6 & $x 2$ \\
\hline & & & 7 & $x 2$ \\
\hline & & & 9 & $x 2$ \\
\hline & & & 12 & - \\
\hline & & & 13 & - \\
\hline \multirow[t]{8}{*}{ Rose Luke } & UJ & 11 & 4 & - \\
\hline & & & 5 & $x 2$ \\
\hline & & & 6 & - \\
\hline & & & 7 & $x 2$ \\
\hline & & & 8 & $x 2$ \\
\hline & & & 9 & - \\
\hline & & & 11 & - \\
\hline & & & 12 & - \\
\hline \multirow[t]{8}{*}{ Zane Simpson } & US & 11 & 4 & - \\
\hline & & & 5 & - \\
\hline & & & 6 & x3 \\
\hline & & & 7 & - \\
\hline & & & 8 & $x 2$ \\
\hline & & & 9 & - \\
\hline & & & 10 & - \\
\hline & & & 12 & - \\
\hline \multirow[t]{6}{*}{ L.L. Goedhals-Gerber } & US & 10 & 6 & $x 3$ \\
\hline & & & 7 & - \\
\hline & & & 9 & $x 2$ \\
\hline & & & 10 & $x 2$ \\
\hline & & & 11 & - \\
\hline & & & 12 & - \\
\hline \multirow[t]{7}{*}{ A. de Bod } & US & 10 & 4 & - \\
\hline & & & 5 & - \\
\hline & & & 6 & $x 2$ \\
\hline & & & 7 & - \\
\hline & & & 8 & $x 2$ \\
\hline & & & 9 & - \\
\hline & & & 10 & $x 2$ \\
\hline \multirow[t]{6}{*}{ Gert Heyns } & UJ & 9 & 5 & - \\
\hline & & & 6 & $x 3$ \\
\hline & & & 7 & $x 2$ \\
\hline & & & 8 & - \\
\hline & & & 9 & - \\
\hline & & & 12 & - \\
\hline
\end{tabular}

TABLE 3 (Continues...): Top 10 productive authors with affiliation and volume numbers in which articles appeared.

\begin{tabular}{lcccc}
\hline Author & Affiliation & Articles & Volume & Number of articles \\
\hline Wesley Niemann & UP & 8 & 10 & x2 \\
& & & 11 & x2 \\
& & 12 & x2 \\
Intaher N. Ambe & UNISA & 7 & 5 & x2 \\
& & & 6 & - \\
& & 7 & x3 \\
& & 11 & - \\
\hline
\end{tabular}

UNISA, University of South Africa; UJ, University of Johannesburg.

TABLE 4: South African academic affiliations of published articles and the number of articles published by authors from these institutions.

\begin{tabular}{lcc}
\hline Institution & Number of articles & Number of articles co-authored \\
\hline UJ & 62 & 12 \\
UNISA & 34 & 7 \\
US & 31 & 4 \\
UP & 13 & 12 \\
VUT & 11 & 6 \\
UKZN & 9 & 4 \\
CSIR & 6 & 3 \\
NWU & 4 & 2 \\
DUT & 3 & 1 \\
CPUT & 2 & - \\
TUT & 2 & - \\
WITS & 1 & - \\
UCT & 1 & - \\
UL & 1 & - \\
UFH & 1 & $\mathbf{5 1}$
\end{tabular}

UJ, University of Johannesburg; UNISA, University of South Africa; US, Stellenbosch University; UP, University of Pretoria; VUT, Vaal University of Technology; UKZN, KwaZuluNatal University; CSIR, Council for Scientific and Industrial Research; NWU, North-West University; DUT, Durban University of Technology; CPUT, Cape Peninsula University of Technology; TUT, Tshwane University of Technology; WITS, University of the Witwatersrand; UCT, University of Cape Town; UL, University of Limpopo; UFH, University of Fort Hare.

Goedhals-Gerber from US, Walters, Luke and Heyns from UJ, as well as Badenhorst-Weiss with Ambe from UNISA and finally Niemann and his network of co-researchers from UP.

\section{Breakdown according to affiliation and nationality}

The affiliations of all authors, from the various academic and research intuitions in South Africa, who contributed articles, are presented in Table 4 . These are presented in order of the number of articles published from the various institutions. As mentioned above, the four top contributors are also from the four universities with strong and dedicated logistics and supply chain management departments. One would have expected to see the CSIR higher up the list, whilst it is encouraging that articles from 'previously disadvantaged' institutions are present.

The employees of private sector companies in South Africa do not publish and are in general not encouraged to publish. The same applies for those in the public sector. Table 5 shows this very clearly. Only a few articles were published by authors from both the private and public sectors over the period 2007-2019; and only one article from a national government department and one from local government. 
TABLE 5: Private and public sector contributions to journal of transport and supply chain management from 2007 to 2019.

\begin{tabular}{lcc}
\hline Private and public sectors & $\begin{array}{c}\text { Number of } \\
\text { articles }\end{array}$ & $\begin{array}{c}\text { Number of articles } \\
\text { co-authored }\end{array}$ \\
\hline SASOL & 1 & 1 \\
RCBM & 1 & - \\
Stewart Scott International engineers & 1 & 1 \\
National Department of Transport & 1 & 1 \\
City of Tshwane & 1 & 1 \\
Aveng & 1 & 1 \\
Exxaro coal & 1 & 1 \\
Chesmans Trade International Co., & 1 & - \\
Cape Town, South Africa & 1 & 1 \\
Aramex South Africa & 2 & - \\
Tega Industries South Africa (Pty) Ltd. & 1 & 1 \\
Private consultants & $\mathbf{1 2}$ & $\mathbf{8}$ \\
\hline Total &
\end{tabular}

What are the reasons for this? Again, one can only speculate. For the majority of those involved in these two sectors, no incentives are provided to publish their work. In addition, within the private sector, a strong sense of competitiveness is felt, whilst confidentiality remains a high priority as well as the protection of intellectual property.

The effort and time spent on drafting a publication is not considered to impact the brand, the image or the bottom line of organisations in these two sectors. A further contributing factor, in the case of the private sector, is the decline in the spending of business enterprise on $R \& D$ (BERD) (see Molotja et al. 2019). The ratio of BERD to gross domestic expenditure on R\&D (GERD) in South Africa has declined to almost $40 \%$ since 2009-2010. With less spending, there is bound to be less research outputs in terms of publications. Many of the articles published in the JTSCM are, however, related to both the private and public sectors and address a variety of issues in these two sectors. These articles, however, were drafted by academics and researchers. It is likewise difficult to determine whether articles were directly commissioned or funded. Some articles are the result of funded projects, but it is not clear whether the drafting of an article was part of the project and, thus, funded in that manner.

International contributions represent involvement in about $20 \%$ of the articles contained in the JTSCM for the period of the analysis (see Table 6). The authors originate from 19 different countries. Many of the articles in the JTSCM, with the involvement of international authors, are co-authored with other authors. Twenty articles were solely contributed by international authors. Of these, five are co-authored with international collaborators. Those 20 articles represent about $10 \%$ of all the articles published.

With logistics and supply chain management being such an important and dynamic discipline, used and implemented by organisations worldwide, 19 countries constitute only $10 \%$ of the 192 countries that are members of the United Nations. The $10 \%$ is, thus, not high. One, however, needs to interpret this in the light of the fact that many international
TABLE 6: Countries of International contributors and the number of articles.

\begin{tabular}{lcc}
\hline Country & Number of articles & Number of articles co-authored \\
\hline United Kingdom & 5 & 5 \\
Sweden & 4 & 1 \\
Australia & 4 & 1 \\
Zimbabwe & 4 & 2 \\
Nigeria & 3 & 1 \\
Namibia & 3 & 2 \\
Mexico & 2 & 1 \\
India & 2 & 1 \\
Ghana & 2 & - \\
United Arab Emirates & 2 & 2 \\
Ethiopia & 2 & 1 \\
France & 1 & 1 \\
Bangladesh & 1 & - \\
Uganda & 1 & - \\
Korea & 1 & 1 \\
Botswana & 1 & - \\
China & 1 & 1 \\
Czech Republic & 1 & - \\
Norway & 1 & 1 \\
\hline Total & 41 & 21 \\
\hline & & \\
\hline & 1 & 2 \\
\hline
\end{tabular}

journals are dedicated to the discipline that publishes articles on this topic.

\section{Collaboration amongst authors}

Aspects of bibliographic analysis can be graphically represented. A range of software tools can be used for this purpose. The software tool, VOSviewer, not only enables the creation of maps based on network data but has the capability of visualising and exploring these maps (VOSviewer 2021). The functionality of VOSviewer enables one to construct networks of scientific publications, scientific journals, researchers, research organisations, countries, key words or terms; and items in these networks, in turn, can be connected by co-authorship, co-occurrence, citation, bibliographic coupling or co-citation links. For the bibliographic analysis, in this article, the network for co-authorship was constructed using VOSviewer. This gives a visual representation of research networks, that is, authors who work together and jointly publish articles.

A bibliographic database was created of the JTSCM data, using Dimensions. As indicated in the introduction of bibliometric analysis, Dimensions is similar to Scopus and WoS, and it does contain data of all 197 JTSCM articles. This database then served as the input to VOSviewer and from this VOSviewer was used to create visualisations of the coauthorship data as well as clusters of research networks. VOSviewer uses different quantitative techniques as part of its functionality.

In Waltman, Van Eck and Noyons (2010), the clustering technique used in the tool is outlined.

As part of the technique, an optimisation problem needs to be solved. Waltman and Van Eck (2013) introduced a smart local moving algorithm for this purpose. 


\section{Network visualisation of co-authorship}

Figure 5 shows the network of co-authorship links between the authors of all the 197 JTSCM articles. VOSviewer has an option to select the minimum number of articles per author. All authors and, thus, all articles are presented in Figure 5. The 'bubbles', or circles, represent authors, also called 'items', and the size of the 'bubble' indicates the number of articles by a specific author. The lines (which are not that clear in Figure 5 as it is small), or links, show the relationship between authors and here it represents co-authorship links. Thus, where there is a line between two authors, they have co-authored one or more articles. Authors, who have co-authored, also tend to be located close to each other on the map shown in Figure 5. Colours indicate clusters of authors who are relatively strongly connected by co-authorship links and, thus, represent research networks or research communities (also referred to as 'clusters').

From Figure 5, one can see that around 10 research networks or communities published articles in the JTSCM. The larger ones coloured in purple, blue, green and reddish represent the research communities from US, UNISA, UP and UJ, respectively. These correlates with the most productive authors or groups as depicted in Table 3. The big scattering of 'bubbles' in Figure 5 indicates that many authors are single authors whilst many have published only one article.

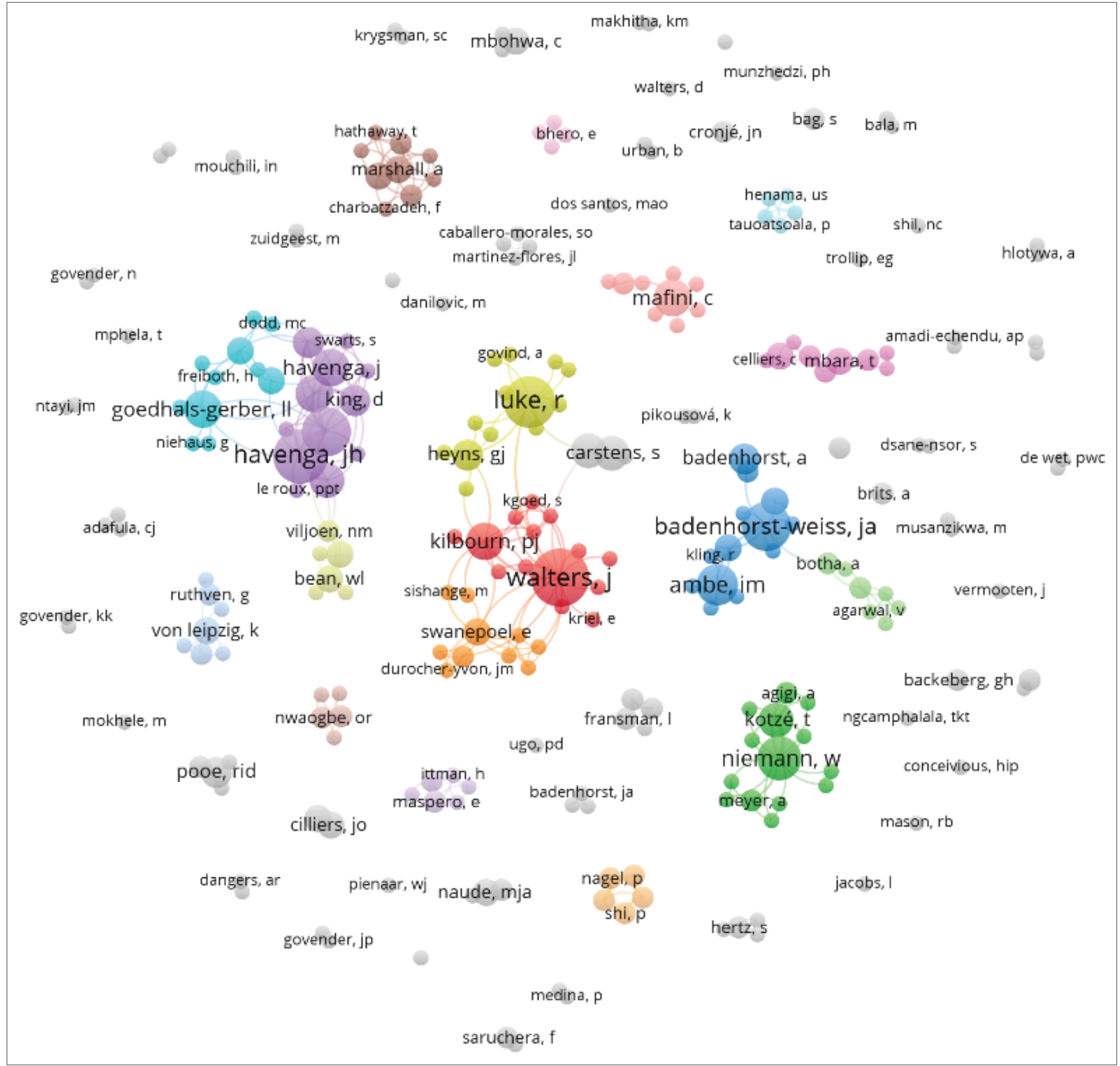

FIGURE 5: Network visualisation of co-authorship network. 


\section{Overlay visualisation of co-authorship}

Overlay visualisation is identical to the network visualisation except that the authors, or items, are coloured differently. The size of a 'bubble' indicates the number of articles the author has published exactly like that in the network visualisation. Each of the 'bubbles', or items, has a 'score'; in this case, the score is the year, or volume, in which the article was published. VOSviewer uses the score to colour a 'bubble' using the default colours. These colours range from blue (i.e. the lowest score in the first year 2007) to green to yellow (i.e. the highest score in the year 2019). The user can also define the colours, but this was not done in this case. If items have neither scores nor user-defined colours, it is not possible to create an overlay visualisation.
Figure 6 shows the overlay visualisation for the JTSCM articles. The colour key, at the top right of the map, shows the colours for the different years. As each year represents a volume of the journal, the year can also be interpreted as a volume. The overlay map, thus, gives an indication of when a specific article was published by using different colours depending on when an article was published.

\section{Density visualisation of co-authorship}

Figure 7 presents a network of co-authorship where the visualisation is shown by density. In this case, the most connected groups of authors are highlighted in the form of 'clusters' or research communities. The attributes used to determine the clusters, or closeness, include the number of

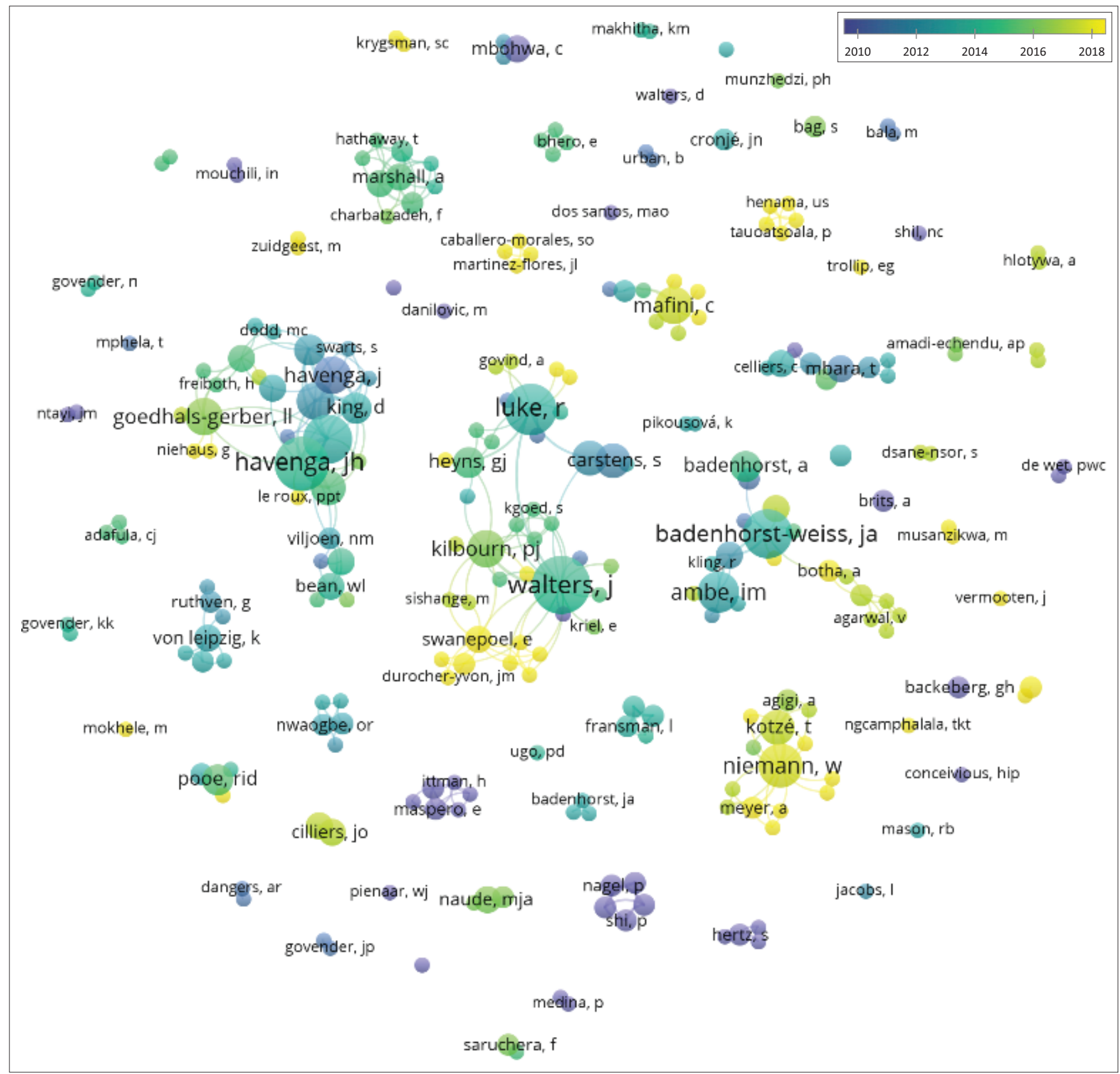

FIGURE 6: Overlay visualisation of co-authorship network. 


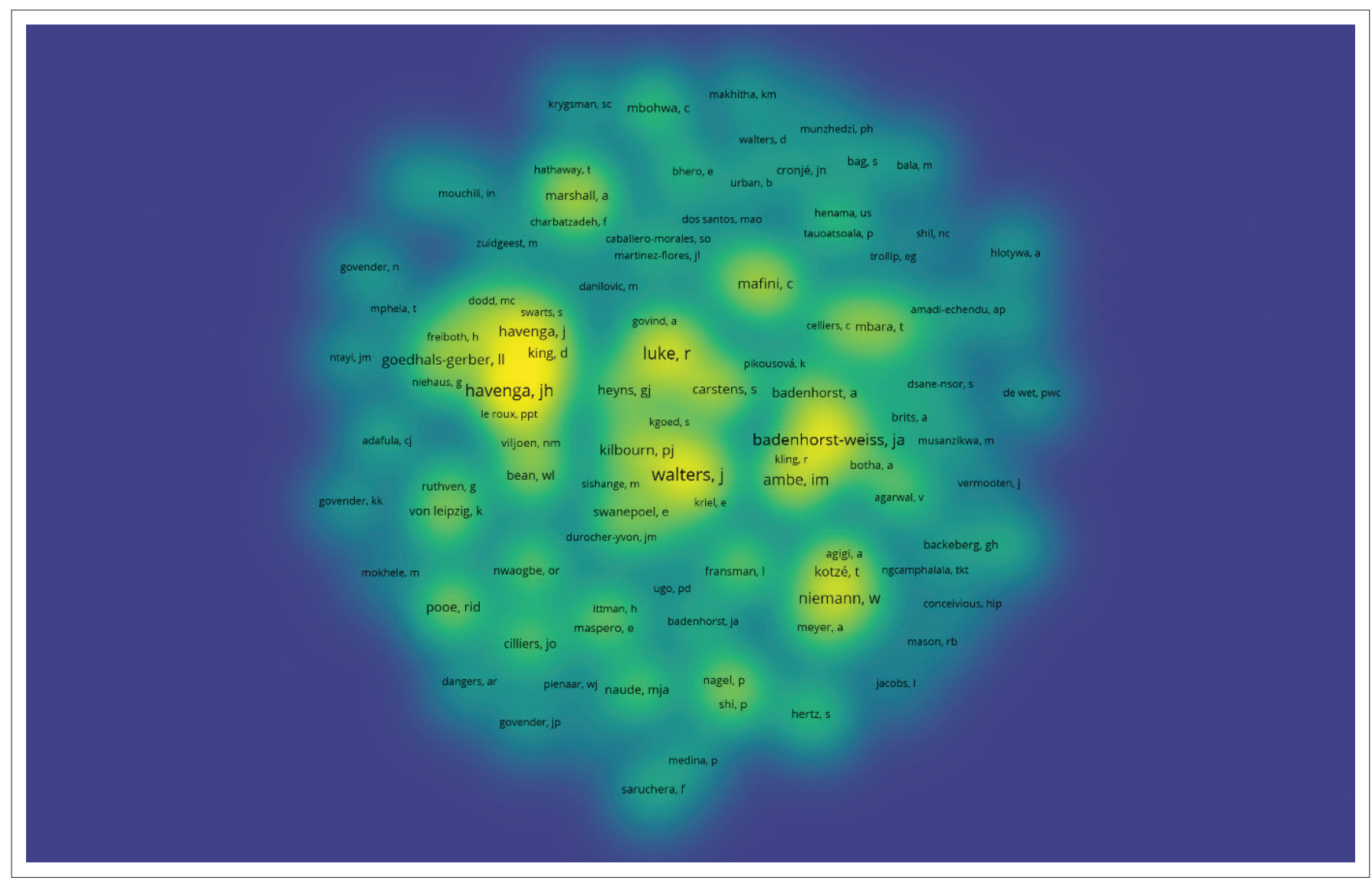

FIGURE 7: Density visualisation of co-authorship network.

articles an author has published, the number of articles an author has co-authored and the institution of the author as well as that of the co-authors. This is represented as clusters in the map where the size of the cluster is largely determined by the number of articles published by the specific network or research community. For Figure 7 , all the authors were considered; thus, everyone who published one or more articles. Five clear clusters can be identified (the bright yellow regions in Figure 7) with several smaller ones. The author with the largest number of studies is Jan H. Havenga with a total of 18 articles of which 15 are co-authored. Of the 15 co-authored articles, the primary co-authors are Zane Simpson and Anneke de Bod. The Havenga research community is shown within the largest cluster. The second largest cluster contains the author, Jackie Walters (14 articles of which 13 are co-authored), and the rest of his network. Rose Luke has a weak connection to this cluster and almost represents a separate cluster. Johanna A. Badenhorst-Weiss, and her research community are also clearly a strong cluster.

Figure 8 is a different density visualisation but here only authors with five or more articles were considered. The five main clusters appear much more visible in this figure. These are the 'Havenga' cluster, the 'Walters' one, 'Badenhorst-Weiss', 'Niemann' and 'Mafini'. The four biggest clusters, again, represent the groups US, UJ, UNISA and UP. These are academics from the four dedicated logistics and supply chain management departments (see productive authors and authors achieving the biggest impact section).

\section{Logistics topics}

Ideally the key words, listed in each article, can be used to determine the transport and supply chain management topics addressed in the articles published over the period 2007-2019. However, for the first seven volumes, no key words are listed for any of the articles. Therefore, the article titles were used, and the following 20 main topical areas were determined:

- Procurement

- Supply chain management

- Green logistics including greening

- Transportation

- Airport and airline aspects

- Freight transport

- Infrastructure

- Outsourcing

- Reverse logistics

- Costs (freight costs, transportation costs, etc.)

- Risk management

- Policy issues

- Maintenance

- Humanitarian logistics

- Sustainability

- Supplier relationship 


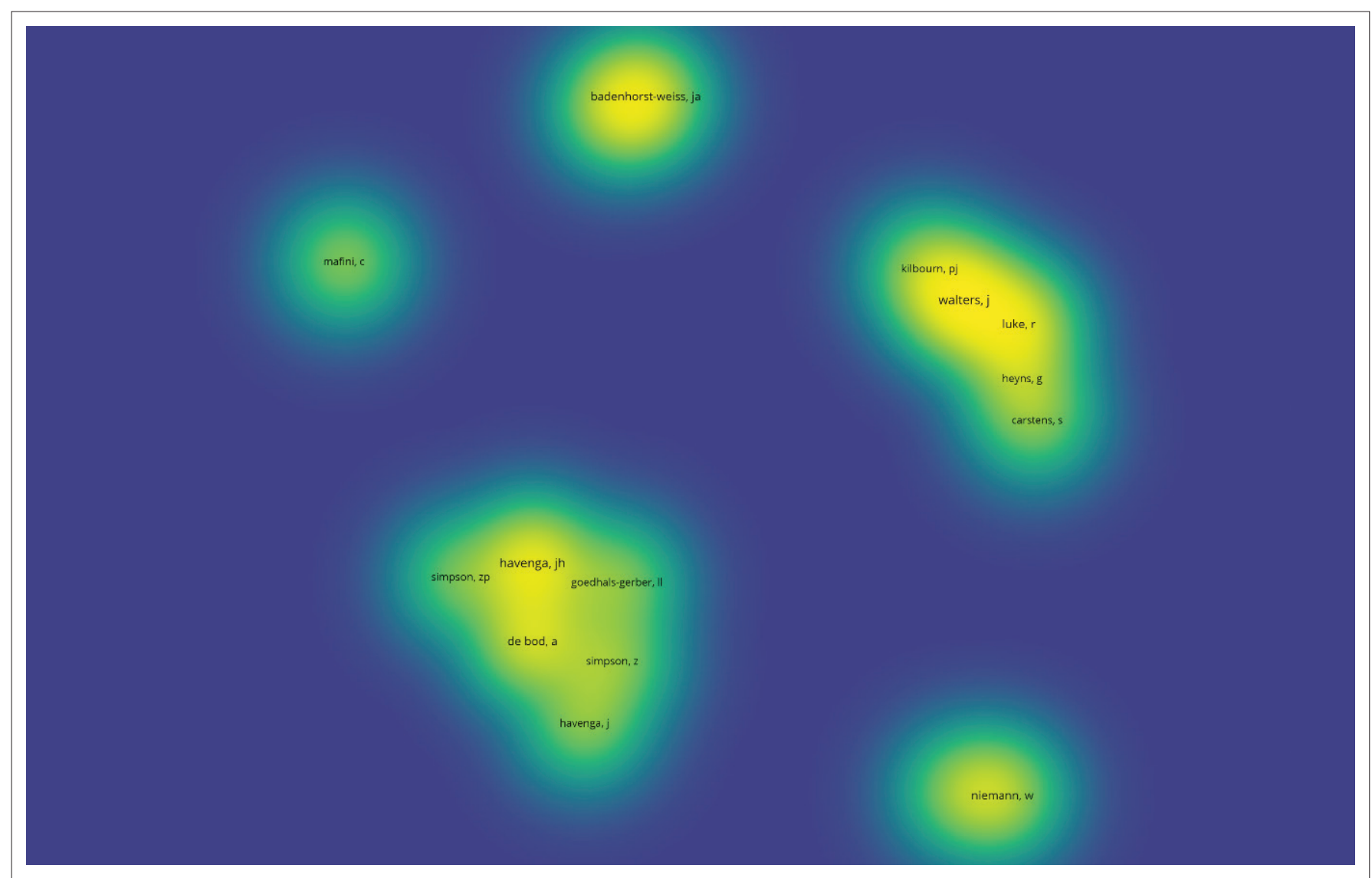

FIGURE 8: Density visualisation of the co-authorship network when authors with five or more articles are considered.

- Intermodal

- Skills development

- Resilience

- Collaboration

The above mentioned is not a one-to-one mapping of articles to topical areas. Some articles are classified into more than one area, whilst many articles do not fall in any of these areas. The range of articles published in the JTSCM, thus, covers many topics in transport and supply chain management. This is not surprising as there are only a few research groups in the country; whilst they do focus on specific expertise areas, the number of articles published by these groups is limited. In many cases, an author would publish only one article on a topic that is either very specialised or it is the topic of a thesis or a case study.

What is noticeable is the lack of articles on more cuttingedge topics. Included amongst these are supply chain digital transformation, related aspects such as artificial intelligence, machine learning, etc., and how these could impact transport, logistics and supply chain management, behavioural aspects within supply chains, the Fourth Industrial Revolution and its impact, big data, analytics, etc. With the current pandemic, COVID-19, one would expect articles on this topic in the future. It is encouraging to note that the editorial of volume 20 is dedicated to this topic (Luke 2020).

\section{Discussion}

The bibliographic analysis conducted gives an interesting view on a range of aspects concerning the journal. Over a 13-year period, 197 articles were published in volumes 1-13, covering a wide spectrum of topics. As of December 2020, the total citation count was 1987 which was obtained using GS. The mean number of citations per article published was, thus, just over 10 . The citations of the top 10 articles add up to 487, reducing the mean for the rest to 8. Only 14 articles that were not cited indicate interest in the articles published in the journal, although the mean citation count remains low. This mean will have to increase substantially to contribute towards the perceived quality and impact of the journal.

Academics were by far the main contributors of articles with around $10 \%$ of these being from elsewhere in the world. A total of 53 single-author articles $(26.9 \%)$ appeared in the JTSCM, with four main pockets of collaboration. The latter are four main academic departments focusing on transport and supply chain management in the country whilst the rest of the collaborations is disjointed pockets of varying sizes. Many of the single authors published only one article over the period.

The lack of contributions from both the private and public sectors is a concern. Practical case studies from the private sector will enrich the content of the journal as well as interest 
in the journal. The public sector can stimulate research if policy-related articles are published.

The aim of the journal is also to share the latest research, new trends, important noteworthy practices as well as case studies. The question then is: has this been achieved? Pockets of latest research have been published such as that by Havenga and co-authors, Luke and Heyns and one or two others; but in general, the material covered in the journal is a conglomerate of a wide range of topics. As the research and academic pool in the country is small, this is what can be expected. Academics have a specific research interest, and they address aspects of it by publishing material on the topic, and this is the trend with almost all academics and researchers. Little, if any, has been published on new trends in the field. The same applies for noteworthy practices and case studies.

With this analysis, access to data, and specifically comprehensive data in a useable form, was problematic. The only database that has the full index of the JTSCM articles is Dimensions.

However, the index does not include key words, since the key words for the first seven volumes of the JTSCM are nonexistent. In addition, the analysis and review were conducted over a period of only 13 years, and an analysis over a longer period would be possible more informative and reliable.

\section{Conclusion}

When the JTSCM was launched in 2007, it gave those involved in transport and supply chain management an outlet to publish their work; and in this regard, the journal filled an important gap in the transport and supply chain management landscape in South Africa. The fact that over a period of 13 years, an average of 15 articles per volume was published is an indication of the impact this journal has made, signifying the need for a journal addressing these important disciplines. A downward trend has been observed in terms of the articles published and that is a concern if this continues. Although no value or goal was set at the outset, the fact that over half a million downloads of JTSCM articles speaks volumes. This is encouraging and is an indication of the value, but also the impact, JTSCM is making - researchers and others want to read the published articles. In addition, the fact that JTSCM is an accredited journal with the Department of Higher Education and Training (DHET), whilst it is indexed on Scopus, shows real progress towards becoming an influential journal. Unfortunately, JTSCM does not have an impact factor yet.

The number of citations of a journal article gives a good indication of its impact. Of the articles in the JTSCM, close to $40 \%$ (77 articles) has 10 or more citations whilst 26 articles have 20 or more citations. Different views exist about what constitutes a good citation number. According to Beaulieu (2015), almost $44 \%$ of all published articles are never cited! To be in the top $24 \%$ of the most cited work worldwide, Beaulieu indicates, an article must have 10 or more citations, and
77 JTSCM articles fall into this category. The number of citations is affected by the fact that time needs to elapse before an article is cited. As a result, 33 articles published in the last 2 years of the analysis have low citations. When citations are analysed, self-citation needs to be considered and the impact of this over the 13-year period is not clear. Nevertheless, based on the number of citations, 1987 obtained via GS, one can conclude that for a relatively 'young' journal, JTSCM has made some impact. It does, however, needs to go a long way to be an influential journal.

There is a one-third to two-third split between the transportrelated and supply chain management-related articles published over the 13-year period. Of these, 91 are of a theoretical nature, 64 empirical articles and 42 applied. Other South African journals can publish both transport and supply chain management articles, while the impact and attraction for transport-related articles by the annual South African Transport Conference possibly play a role in the fact that there are a lower number of transport-oriented studies.

Transport, transportation and related policy issues are covered in 24 articles. A wide range of transport matters are addressed in these. One of the articles (Walters 2014), which address transport policy issues, is the fifth on the citation list. All of these must point to the fact that transport is an important research area as well as critical for both public and private sectors.

With his bibliographic analysis, the main objective was to obtain a sense of the impact this journal has made and is making. With the substantial number of citations, as well as the huge number of abstract and article views, there is no doubt that the journal is making a significant impact.

\section{Acknowledgements}

The author would like to express his appreciation towards Dr Nees Jan van Eck from the University of Leiden for his advice and recommendation to use Dimensions.

\section{Competing interests}

The author declares that he has no financial or personal relationship that may have inappropriately influenced him in writing this article.

\section{Author's contributions}

H.W.I. is the sole author of this research article.

\section{Ethical considerations}

This article followed all ethical standards for research without direct contact with human or animal subjects.

\section{Funding information}

The author received no financial support for the research, authorship and/or publication of this article. 


\section{Data availability}

Data were obtained from two main formal sources: (1) Journal of Transport and Supply Chain Management website - https:/ / jtscm.co.za/index.php/jtscm and (2) Google Scholar scholar.google.com.

\section{Disclaimer}

The views and opinions expressed in this article are those of the author and do not necessarily reflect the official policy or position of any affiliated agency of the author.

\section{References}

Bar-llan, J., 2010, "Citations to the "introduction to informetrics" indexed by WOS Scopus and Google Scholar', Review of Scientometrics 82(3), 495-506. https://doi. org/10.1007/s11192-010-0185-9

Beaulieu, L., 2015, 'How many citations are actually a lot of citations?', Ruminating personal website posted on 12 November 2015, viewed 06 March 2021, from https://lucbeaulieu.com/2015/11/19/how-many-citations-are-actually-a-lot-ofcitations/\#: :text=With\%2010\%20or\%20more\%20citations,manuscript\%20is\%20 clearly\%20below\%2010!

Council for Scientific and Industrial Research (CSIR), 2002, Workshop on operations research for global logistics involving Africa, CSIR conference centre, Pretoria, 05-08 August 2002, pp. 1-17

Council for Scientific and Industrial Research (CSIR), 2005, The state of logistics surveys 2004 to 2013, CSIR, Pretoria, viewed 02 December 2019, from https:// www.csir.co.za/state-logistics-survey-south-africa-gearing-change.

Ghalehkhondabi, I., Ahmadi, E. \& Maihami, R., 2020, 'An overview of big data analytics application in supply chain management published in 2010-2019', Production 30 e20190140. https://doi.org/10.1590/0103-6513.20190140

Hajduk, S., 2017, 'Bibliometric analysis of publications on city logistics in International scientific literature', Procedia Engineering 182, 282-290. https://doi.org/10.1016/ j.proeng.2017.03.194

Jiang, C., Bhat, C.R. \& Lam, W.H.K., 2020, 'A bibliometric overview of transportation research, Part B: Methodological in the past forty years (1979-2019)' Transportation Research Part B: Methodological 138, 268-291. https://doi. org/10.1016/j.trb.2020.05.016

Kazemi, N., Modak, N.M. \& Govindan, K., 2019, 'A review of reverse logistics and closed loop supply chain management studies published in IJPR: A bibliometri and content analysis', International Journal of Production Research 57(15-16), 4937-4960. https://doi.org/10.1080/00207543.2018.1471244

Kruger, H.A. \& Van Vuuren, J.H. (eds.), 2019, Operations research in South Africa - The first 50 years, African Sun Media, Stellenbosch.

Kruger, S., 2013, 'Scientific contributions in the field of transport and supply chain management', Journal of Transport and Supply Chain Management 7(1), a128, 2 pages. https://doi.org/10.4102/jtscm.v7i1.128

Kujawa, B., 2007, 'Editorial', Journal of Transport and Supply Chain Management 1(1), a2. https://doi.org/10.4102/jtscm.v1i1.2

Luke, R., 2020, 'The impact of COVID-2019 on transport in South Africa', Journal of Transport and Supply Chain Management 14(0), a545. https://doi.org/10.4102/ jtscm.v14i0.545

Mas-Tur, A., Kraus, S., Brandtner, M., Ewert, R. \& Kürsten, W., 2020, 'Advances in management research: A bibliometric overview of the review of managerial science', Review of Managerial Science 14, 933-958. https://doi.org/10.1007/ s11846-020-00406
Michigan State University (MSU), 2020, PubMed, Web of Science, or Google Scholar? A behind-the-scenes guide for life scientists: Which one is best: PubMed, Web of Science, or Google Scholar?, viewed on 17 Desember 2020, from https://libguides. Science, or Google Scholar?, viewed on
lib.msu.edu/pubmedvsgooglescholar

Modak, N.M., Merigó, J.M., Weber, R., Manzor, F. \& Ortúzar, J., 2019, 'Fifty years of transportation research journals: A bibliometric overview', Transportation Research Part A: Policy and Practice 120, 188-223. https://doi.org/10.1016/j.tra.2018.11.015

Molotja, N., Parker, S. \& Mudavanhu, P., 2019, 'Patterns of investing into business R\&D in South Africa', Foresight and $S T 1$
org/10.17323/2500-2597.2019.3.51.60

Movahedipour, M., Yang, M., Zeng, J., Wu, X. \& Salam, S., 2016, 'Optimization in supply chain management, the current state, and future directions: A systematic review and bibliometric analysis', Journal of Industrial Engineering and Management 9(4), 933-963. https://doi.org/10.3926/jiem.2035

Ren, R., Hu, W., Dong, J., Sun, B., Chen, Y. \& Chen, Z., 2019, 'A systematic literature review of green and sustainable logistics: Bibliometric analysis, research trend review of green and sustainable logistics: Bibliometric analysis, research trend
and knowledge taxonomy', International Journal of Environmental Research and and knowledge taxonomy', International Journal of Environmental
Public Health 17(1), 261. https://doi.org/10.3390/ijerph17010261

Republic of South Africa 2005a, National advanced manufacturing technology strategy, Department of Science and Technology, Pretoria, viewed on 05 December 2019,
from https://www.gov.za/sites/default/files/gcis_document/201409/ dstadvancedmanufacturingtechnologystrategy310320050.pdf.

Republic of South Africa 2005b, National freight logistics strategy, Department of Transport, Pretoria.

Rosenberg, N., 1976, 'On technological expectations', The Economic Journal 86(343), 523-535. https://doi.org/10.2307/2230797

Scimago Institutions Rankings (SJR), 2020, Scimago journal \& country rank 1996-2019, viewed 06 March 2021, from https://www.scimagojr.com/countryrank.php.

Scopus, 2020, 'What is Scopus preview?', Scopus, viewed 06 March 2021, from https://service.elsevier.com/app/answers/detail/a_id/15534/supporthub/ scopus/\#tips.

Tanrıverdi, G., Bakır, M. \& Merkert, R., 2020, 'What can we learn from the JATM literature for the future of aviation post Covid-19? - A bibliometric and visualization analysis', Journal of Air Transport Management 89, 101916. https:// doi.org/10.1016/j.jairtraman.2020.101916

Van Leeuwen, T., 2004, 'Descriptive versus evaluative bibliometrics', in H.F. Moed, W. Glänzel \& Y. Schmoch (eds.), Handbook of quantitative science and technology research: The use of publication and patent statistics in studies of S\&T systems, pp. 373-378, Kluwer, Dordrecht.

Van Vuuren, JH., 2019, 'The Society's Scholarly Journal, ORiON', in H.A. Kruger \& J.H. van Vuuren (eds.), Chapter 7: Operations Research in South Africa - The first 50 Years, African Sun Media, Stellenbosch.

VOSviewer, 2021, 'Welcome to VOSviewer', VOSviewer visualizing scientific landscapes, viewed 28 December 2020, from https://www.vosviewer.com/.

Walters, J., 2014, 'Public transport policy implementation in South Africa: Quo vadis?', Journal of Transport and Supply Chain Management 8(1), a134. https://doi. org/10.4102/jtscm.v8i1.134

Waltman, L., \& Van Eck, N.J., 2013, 'A smart local moving algorithm for largescale modularity-based community detection', European Physical Journal B 86(11), 471.

Waltman, L., Van Eck, N.J., \& Noyons, E.C.M., 2010, 'A unified approach to mapping and clustering of bibliometric networks', Journal of Informetrics 4(4), 629-635

Wang, C., Lim, M.K. \& Lyons, A., 2019, 'Twenty years of the International journal of logistics research and Applications: A bibliometric overview', International Journal
of Logistics Research and Applications 22(3), 304-323. https://doi.org/10.1080/ 13675567.2018.1526262

Wang, J.-J., Chen, H., Rogers, D.S., Ellram, L.M. \& Grawe, S.J., 2016, 'A bibliometric analysis of reverse logistics research (1992-2015) and opportunities for future research', International Journal of Physical Distribution \& Logistics Management 47(8), 666-687. https://doi.org/10.1108/IJPDLM-10-2016-0299

Web of Science, 2019, Journal citation reports, viewed 13 December 2020, from https://tinyurl.com/yywksu64.

Yalcin, H., Shi, W. \& Rahman, Z., 2020, 'A review and scientometric analysis of supply chain management (SCM)', Operations and Supply Chain Management 13(2), 123-133. https://doi.org/10.31387/oscm0410257 